\section{Desenvolvimento territorial \\ e desigualdades socioespaciais: \\ estratégias para superação \\ das disparidades territoriais?}

Tatiane Marina Pinto de Godoy

Professora da Universidade Federal

de São João del Rei, Brasil.
Economía Social y Solidaria /

Perspectivas
RECEPCIÓN: 24/06/15

ACEPTACIÓN FINAL: 29/07/15

\section{Resumo}

As estratégias de consolidação da economia solidária contidas nos planos e projetos de políticas públicas no Brasil trazem para o debate a dimensão espacial. A partir de noções que aliam a espacialidade à noção de desenvolvimento propõe-se uma discussão dos termos desenvolvimento local e desenvolvimento territorial. Por conseguinte, o artigo formula uma perspectiva de análise, amparada em revisão bibliográfica e em observações não sistematizadas. Trata-se, portanto, de um ensaio oriundo de preocupações teórico-conceituais. Compreende-se que a escolha de termos para referenciar estratégias espaciais da economia solidária comporta projetos. Parte-se do pressuposto que a teorização crítica do mundo, a partir da matriz do pensamento marxista, tem como uma de suas dimensões a praxis, ou seja, a consciência lógica da possibilidade a partir do presente. A ideia que se busca desenvolver é que a diferença entre os termos comportam projetos diferentes para a economia solidária.

Palavras-chave

- economia solidária

- desenvolvimento territorial

- desigualdades socioespaciais

\section{Resumen}

Las estrategias de consolidación de la economía solidaria contenidas en planes y proyectos de políticas públicas en Brasil han provocado un debate sobre la dimensión espacial. A partir de conceptos que integran la espacialidad con la noción de desarrollo, se propone una discusión de los términos de desarrollo local y el desarrollo territorial. Por lo tanto, el artículo formula una perspectiva de análisis, amparada en una revisión bibliográfica y en observaciones no sistematizadas. Se trata de un ensayo que surge de las preocupaciones teóricoconceptuales. De allí que la elección de términos para referenciar las estrategias espaciales de la economía solidaria sostengan proyectos diferenciados. Se parte de suponer que la teorización crítica del mundo, a partir del pensamiento marxista, tiene como una de sus dimensiones la praxis, es decir, la conciencia lógica de la posibilidad desde el presente. La idea que se busca desarrollar es que la diferencia entre los términos comporta proyectos distintos para la economía solidaria.

Palabras clave

- economía solidaria

- desarrollo territorial

- desigualdades socioespaciales
Para citación de este artículo Pinto de Godoy, T. M. (2015). Desenvolvimento territorial e desigualdades socioespaciais: estratégias para superação das disparidades territoriais? En Revista +E versión digital, (5), pp. 42-49. Santa Fe, Argentina: Ediciones UNL. 


\section{Introdução}

Nota-se, a partir das leituras de referências teóricas e dos materiais institucionais produzidos pelo Estado brasileiro, uma contradição na proposta de uma economia amparada em princípios de cooperação e solidariedade usando o conceito de "desenvolvimento local". Um estudo mais pormenorizado sobre o desenvolvimento local revela que ele significa uma estratégia de competição entre lugares para abrigar os vetores do desenvolvimento capitalista.

A partir do referencial da Geografia Crítica, retoma-se a categoria território para, aliada ao conceito de desenvolvimento, buscar relações entre o sentido de identidade e pertencimento e os princípios de solidariedade e cooperação da Economia Solidária. Embora seja um conceito geográfico, o território tem ampla tradição em outras áreas de conhecimento. Haesbaert (2009:37) apresenta as ênfases que as diferentes ciências empregam ao conceito de território. É importante saber de onde partem as compreensões sobre o território quando se trabalha numa equipe multidisciplinar. Essa compreensão também ajuda a mapear as diferentes designações de território e de desenvolvimento territorial que estão sendo aplicadas aos estudos sobre a Economia Solidária. Assim, conforme Haesbaert (2009):

- O geógrafo enfatiza a materialidade do território em suas múltiplas dimensões (que deveria incluir a interação sociedade-natureza); - O cientista político enfatiza a construção do território a partir das relações de poder (na maioria das vezes ligada à concepção de Estado);

- O economista, que prefere a noção de espaço à de território, percebe-o muitas vezes como um fator locacional ou como uma das bases da produção (enquanto força produtiva);

- O antropólogo destaca sua dimensão simbólica, principalmente nos estudos das sociedades tradicionais;

- O sociólogo enfoca o território a partir de sua intervenção nas relações sociais, em sentido amplo;

- O psicólogo, finalmente, incorpora o território no debate da construção da subjetividade ou da identidade pessoal, ampliandose até a escala do indivíduo.
Embora Haesbaert designe à Geografia uma leitura do território que enfatiza a sua materialidade em múltiplas dimensões e que deveria incluir a interação sociedade-natureza, nossa concepção parte da materialidade do território como um produto social. Ou seja, mais do que uma relação entre sociedade e natureza, compreendemos que o território é produto de relações sociais e que são as práticas sociais que dão forma e conteúdo ao território. No capitalismo essas relações sociais são mediadas na busca incessante pela reprodução ampliada do capital. Na economia solidária as relações sociais são mediadas pela reprodução do trabalho e de condições dignas de reprodução da vida. Cabe, portanto, investigar se as práticas socioespaciais da economia solidária produzem territórios que não se caracterizam pela desigualdade, característica do desenvolvimento geográfico desigual.

\section{Desigualdades socioespaciais: materialismo histórico- geográfico como abordagem teórico metodológica}

No capitalismo a reprodução das relações sociais se assenta numa forma de organização do trabalho, de distribuição dos meios de produção e de apropriação da maisvalia, que extrapolou o espaço da produção e atingiu todos os níveis da vida social. Como produto de uma sociedade desigualmente constituída em função do lugar que cada grupo ocupa na reprodução do modo de produção capitalista, as desigualdades socioespaciais manifestam-se concretamente nas diferenças regionais, na fragmentação do espaço urbano e na concentração territorial da riqueza.

Distinguidas as devidas intencionalidades na produção do espaço de cada lugar, há um comando geral que direciona a produção e a reprodução do espaço segundo os objetivos da acumulação ampliada do capital. $O$ atendimento das demandas do capital distingue os lugares segundo suas possibilidades de reprodução das condições da acumulação ampliada e configura o que hoje se entende pelas diferenciações socioespaciais. 


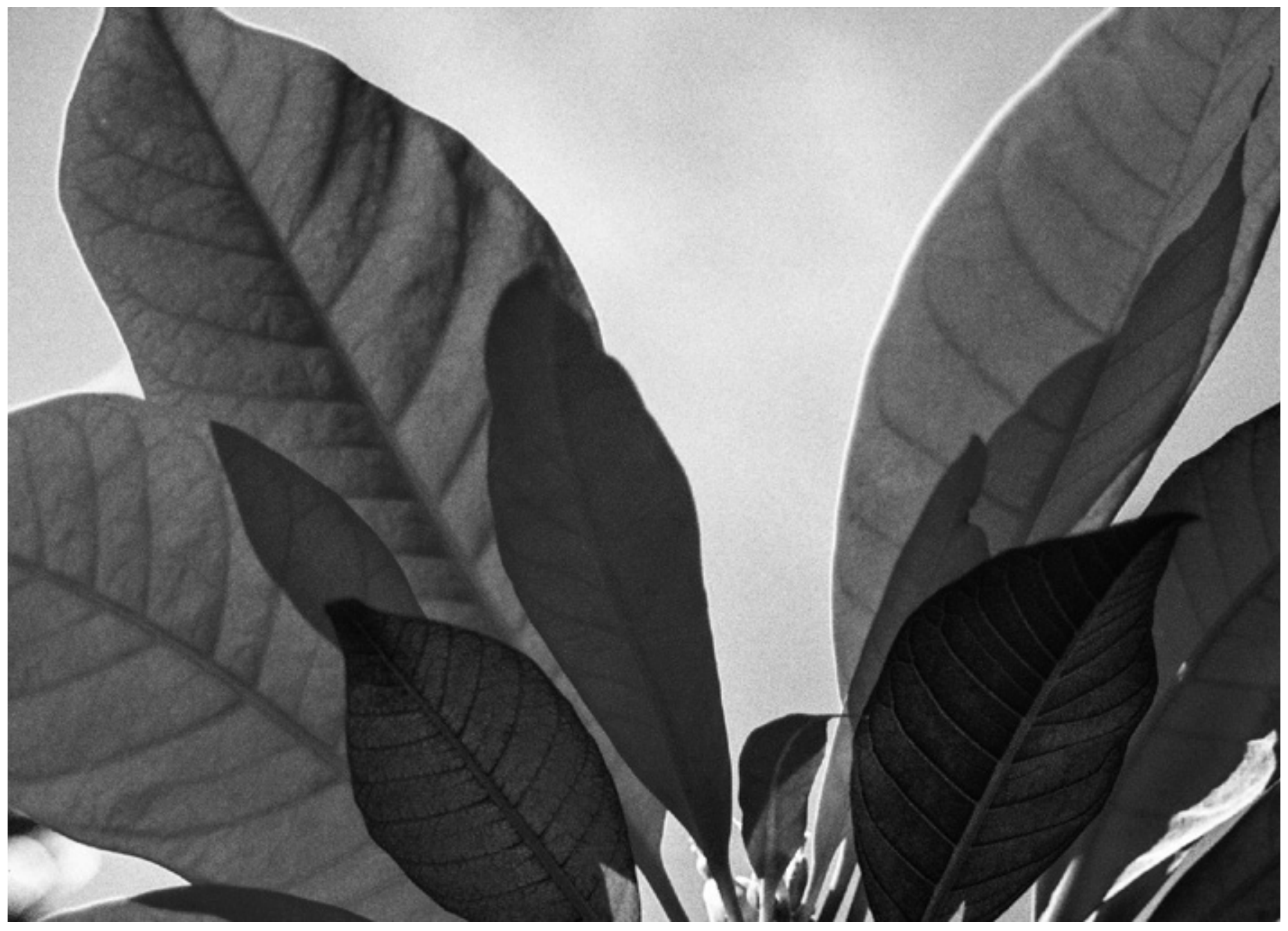


Carlos (2007) enfatiza que a diferenciação espacial explicita uma concepção de espaço que vai além do entendimento da simples localização dos fenômenos, avançando para o entendimento de que o espaço é produto de relações sociais.

Entender a forma como se produz e reproduz a economia solidária implica estabelecer seus intrincados elos com o sistema capitalista. Uma das contribuições teóricas está na compreensão das desigualdades socioespaciais como produto e condição das desigualdades sociais imanentes ao modo de produção capitalista. Essa argumentação teórica fundamenta-se na teoria segundo a qual o espaço não é reflexo ou palco da sociedade, mas constituise da sociedade, materializa as diferenciações sociais e as lutas de classe e condiciona a reprodução das relações sociais.

O conhecimento das relações constituintes da produção espacial, alicerçadas no modo de produção capitalista hegemonicamente em vigor, são pressupostos teóricos para formulação de um conhecimento das condições em que se produzem e reproduzem as relações sociais na Economia Solidária. Assim, é importante reconhecer a realidade que nos cerca e compreender o processo histórico que a produziu.

A noção de "desenvolvimento geográfico desigual" como centro explicativo das diferenciações socioespaciais, esclarece a existência de uma sociedade de classe que diferencia seus membros a partir do lugar que ocupam, tanto na produção, quanto na distribuição da riqueza gerada.

A divisão de classes produz a materialidade da divisão espacial do trabalho. A tarefa social de cada indivíduo condiz com seu lugar no espaço. A posição social também é a posição material na dimensão social. No espaço urbano, caracterizado pela divisão centro-periferia, o lugar ocupado pelas diferentes classes sociais decodifica as relações existentes na produção da cidade. É na escala do lugar, enquanto dimensão prático-sensível das relações sociais, que mais claramente se manifesta a posição ocupada por cada classe social. Mas, no espaço nacional e no espaço mundial, por meio das regionalizações das áreas de interesse do capital, também estão evidentes as diferenciações espaciais como produto das trocas desiguais e combinadas do sistema capitalista de produção.

Entender que as desigualdades socioespaciais são condição para a reprodução do capitalismo, enquanto modo de produção hegemônico, é tão importante quanto entender que as desigualdades sociais são condição da reprodução ampliada do capital. É fundamental compreender que é sobre a desigualdade que o capitalismo se reproduz e que o espaço é a base material necessária, mesmo que estejamos presenciando o triunfo do capitalismo financeiro onde parece que o capital não ocupa lugar. Se a circulação de bens e serviços parecem não mais respeitarem as fronteiras políticas (embora as barreiras alfandegárias e a políticas protecionistas nos mostrem o contrário), a circulação de pessoas está sujeita aos limites territoriais. Os territórios existem, mesmo que no discurso neoliberal sejam negados pelo fim das fronteiras econômicas. E esses territórios estão articulados numa hierarquia definida a partir dos interesses do capital. Essa hierarquia se dá no plano mundial, no plano nacional, nas diferenças regionais e nas diferenças intraurbanas. Se temos populações pobres e ricas, temos territórios pobres e ricos. Temos as favelas, os conjuntos habitacionais, os bairros de infraestrutura precária, os condomínios fechados, os bairros de alto padrão, os edifícios modernos e inteligentes, as áreas requalificadas, todos numa mesma cidade dando materialidade e lugar as diferentes classes sociais. No campo, o território do agronegócio acumula a riqueza que se opõe a precariedade das condições vividas pelos assentamentos e áreas de ocupações do movimento sem terra e pela agricultura familiar.

O desenvolvimento territorial tem por finalidade reverter essas desigualdades socioespaciais? A economia solidária tem a possibilidade de mudar as condições materiais de vida de comunidades que trabalham com os seus princípios? Por qual modelo de desenvolvimento a economia solidária se pauta? Ele condiz com o que se entende por desenvolvimento local ou territorial? Qual é a diferença entre o local e o territorial?

\section{Economia solidária como uma proposta anticapitalista e sua relação com o território}

Estudar espaços que se pautam pelas formas da democracia participativa, seja ela política ou econômica, é um desafio onde o capitalismo avança a passos longos, cooptando experiências potencialmente embrionárias de uma nova forma de reprodução social. É um desafio metodológico analisar, interpretar e construir um pensamento baseado em práticas que são invisibilizadas pela hegemonia do modo de produção capitalista. A teoria crítica nas ciências sociais, de um modo geral, tem produzido um conhecimento revelador dos estratagemas capitalistas para a execução do projeto da globalização. Mas como saber se as experiências relacionadas às alternativas a essa globalização hegemônica estão reproduzindo anseios que se diferenciam da busca pelo acesso ao consumo dirigido?

Faz-se necessário pôr em evidência as experiências populares que estão emergindo onde o capitalismo fez mais vítimas do que favorecidos pelo seu sistema de apropriação privada da riqueza construída coletivamente. Parece-nos evidente, neste momento, que são nos lugares economicamente menos privilegiados que estão as possibilidades mais concretas de estabelecimento de formas de viver baseadas numa organização da vida social pautada pela apropriação coletiva da riqueza produzida e pela escolha coletiva do destino histórico de suas comunidades. Mas para que o conhecimento dê conta de revelar toda essa potencialidade é preciso estabelecer meios legítimos de cognição das experiências. A teoria crítica tem de buscar, incessantemente, a superação dos dogmas científicos, estabelecer uma interlocução 
com o conhecimento popular e formular novos conceitos que traduzam não apenas o que está aparente na paisagem social. Ela deve, também, ser capaz de revelar o que existe e ainda não é visto. Não é possível interpretar as experiências contra-hegemônicas com conceitos, categorias e paradigmas hegemônicos, porque eles sempre darão às experiências o caráter de alternativa inferior ao capitalismo, invisibilizando a construção de outro modo de produzir e de viver.

Estabelecer uma leitura espacial da economia solidária tem sido o mote de nossas pesquisas. Compreendendo que as relações sociais se materializam em relações espaciais, buscamos construir uma análise que ofereça contribuição analítica sobre as iniciativas de grupos de trabalhadores que se associam para produzir mercadorias e serviços buscando superar a separação entre capital e trabalho. Desde as primeiras investigações buscamos referencial nas teorias sobre a espacialização da economia para tentar compreender o fenômeno da economia solidária no Brasil. Ainda que algumas aproximações sejam possíveis como, por exemplo, daquelas teorias sobre o desenvolvimento endógeno, temos constatado que é necessário construir um novo referencial que atenda as especificidades de uma economia que se baseia em princípios diferentes daqueles que orientam os fundamentos do capitalismo. A economia solidária, segundo Paul Singer, refere-se a organizações de produtores, consumidores, poupadores, entre outros, que se distinguem por duas especificidades: estimulam a solidariedade entre os membros mediante a prática da autogestão, e praticam a solidariedade para com a população trabalhadora em geral, com ênfase na ajuda aos mais desfavorecidos (Singer, 2003:116). Uma discussão importante em torno das contribuições de Singer se faz mediante seu entendimento da economia solidária como um outro modo de produção. Essa afirmação aparece em Singer (2002:10), quando ele contrapõe o modo de produção capitalista, cujos princípios são o direito de propriedade individual aplicado ao capital e o direito à liberdade individual, ao modo de produção da Economia Solidária, cujos princípios básicos são a propriedade coletiva ou associada do capital e o direito à liberdade individual. Essa mesma expressão da economia solidária como um modo de produção e distribuição está presente em Singer \& Sousa Santos:

"A economia solidária surge como modo de produção e distribuição alternativo ao capitalismo, criado e recriado periodicamente pelos que se encontram (ou temem ficar) marginalizados do mercado de trabalho). A economia solidária casa o princípio da unidade entre posse e uso dos meios de produção e distribuição (da produção simples de mercadorias) com o princípio da socialização destes meios (do capitalismo). (...) O modo solidário de produção e distribuição parece à primeira vista um híbrido entre o capitalismo e a pequena produção de mercadorias. Mas na realidade, ele constitui uma síntese que supera ambos" (2003:13).
A partir de nossos estudos compreendemos que, a economia solidária consiste em uma forma de produção, distribuição, comercialização, troca, consumo e finanças, de base cooperativista e autogestionária, tendo como finalidade a reprodução do trabalho associado e de um outro modo de viver. Essa forma de produção envolve a dimensão social, econômica, política, cultural e espacial, onde se inserem com a perspectiva da construção de uma sociedade solidária e democrática, reafirmando a emergência de atores sociais com a emancipação dos trabalhadores como sujeitos históricos. Entendemos que a economia solidária tem duas dimensões: - Enquanto conceito, ela significa um conjunto de ações de caráter econômico, político e cultural, definidoras de uma outra forma de apropriação do valor produzido pelo trabalho;

- Enquanto prática econômica ela se materializa nas formas das cooperativas, das associações, dos grupos informais que estabelecem relações sociais baseadas nos princípios da solidariedade econômica, social e política, desenvolvendo uma democracia participativa, pelo menos no que diz respeito à gestão do espaço da produção, troca, distribuição e consumo.

É importante destacar a diferença entre economia solidária e economia popular. Se a economia solidária consiste numa forma de organização do trabalho e da produção que se assenta na autogestão e na organização coletiva dos trabalhadores, a economia popular se organiza a partir de trabalhadores individuais, geralmente empreendimentos individuais, onde não existe a relação patrão-empregado, mas sem a perspectiva de associação ou cooperação entre trabalhadores e empreendimentos. É importante essa distinção porque há um projeto político da economia solidária definido a partir de uma série de instâncias de participação popular e cidadã por meio dos fóruns e plenárias organizadas pelo movimento de economia solidária e também por meio dos conselhos e conferências convocados pelo Estado. O projeto político da economia solidária expresso na Carta Política da V Plenária Nacional de Economia Solidária, realizada em dezembro de 2012, afirma que ela tem como princípio a autogestão, a solidariedade, o reconhecimento e valorização dos saberes tradicionais sendo uma estratégia de desenvolvimento sustentável e solidário, que não se confunde com o microempreendedorismo individual, nem com a economia criativa, nem com a economia verde.

Outras distinções se fazem importantes para que se compreenda o projeto político que os atores da economia solidária defendem no Brasil:

- Em relação ao terceiro setor, conceito que surge no contexto anglo-saxão, cuja ideia central é a da filantropia, particularmente nos EUA, com uma ação redistributiva das organizações sem fins lucrativos, paralela à ação estatal nesse campo.

- Em relação à economia social - é formulada no contexto europeu, em que o Estado-Providência é a base do enfrentamento dos problemas sociais, desenvolvendo-se aí uma economia com 
fins sociais, baseada em grandes fundações, associações e cooperativas, que atuam, hoje, como "apêndice do Estado". A economia solidária tem algumas afinidades com essas ideias, mas, apresenta, sobretudo, particularidades que a afirmam como conceito e prática. Ela tem herança histórica comum com a economia social europeia, com ênfase especial sobre o aspecto democrático da organização do trabalho, em que predomina o estatuto associativista e, em alguns casos, o cooperativista. As iniciativas de economia solidária articulam a dimensão econômica, social e política em uma ação coletiva, em experiências que potencializam transformações sociais mais amplas.

\section{Distinções entre desenvolvimento local e desenvolvimento territorial}

A displicência no emprego dos termos território e local para designar a escala dos projetos de desenvolvimento têm causado alguns equívocos, sob o nosso ponto de vista. Mais do que uma escala de atuação, o emprego de um ou outro termo agrega significados diferentes a proposta de desenvolvimento. O local, em si, não é um conceito, mas uma escala, assim como mundial, nacional e regional. Já o território é um conceito geográfico que, juntamente com os conceitos de região, paisagem e lugar formam o escopo de análise de processos que compreendem o espaço geográfico. O conceito de território é confundido com o de espaço geográfico quando não se tem uma leitura profunda que permita destacar os limites tênues que os distinguem. Outra característica é que o território não pode ser estudado historicamente. Ele é produto de processos históricos e, portanto, a categoria tempo se faz como uma referência necessária.

Embora o local seja uma escala, quando se agrega a ele o termo desenvolvimento o que se tem é uma ideia de que não mais necessariamente passa pelo Estado Nação a definição de planos e ações para alcançar o desenvolvimento. A ideia de desenvolvimento local é descentralizar. É também a ideia de desenvolvimento endógeno, ou seja, a partir de agentes locais. O desenvolvimento territorial também tem essas características.
Mas a ideia que temos buscado desenvolver é que a diferença entre desenvolvimento local e desenvolvimento territorial está no projeto de sociedade que cada um contempla ou, que pelo menos a ideia de desenvolvimento territorial poderia contemplar. $O$ desenvolvimento local surge enquanto estratégia de superação das crises do capitalismo, mas sem questioná-lo. É uma maneira de continuar no jogo do capitalismo que se define pela desigualdade, pela concentração e pela diferenciação: desigualdade social, que é ao mesmo tempo espacial, ou seja, é socioespacial. E subordinarse ao capitalismo tal como ele é só que tentando estar do lado dos "desenvolvidos" e não mais dos "não-desenvolvidos". O desenvolvimento territorial pode ter uma outra perspectiva. Aquela de tentar não se encaixar no jogo do capitalismo, mas a partir do estabelecimento de novas relações sociais, econômicas, políticas, culturais e espaciais pautadas por valores diferentes. Nesse sentido, aliado aos princípios da Economia Solidária, pensamos que temos que usar o conceito de desenvolvimento territorial porque a ideia que o desenvolvimento local carrega consigo já está contaminada pelo princípio da competitividade entre os locais, ou como salientam alguns geógrafos críticos, pela guerra dos lugares.

O termo desenvolvimento territorial tem sido usado em diferentes contextos como forma de explicitar a articulação de iniciativas da economia solidária com os espaços onde estas estão inseridas. Apontado como uma estratégia, o termo aparece tanto em textos acadêmicos quanto em editais públicos para financiamento de atividades de empreendimentos e órgãos de fomento.

Mais do que um conceito geográfico, o território é uma condição para o desenvolvimento. Mas o território também é condição de vida para as pessoas que nele vivem. No desenvolvimento capitalista o território é exaurido de suas riquezas. O modelo de desenvolvimento exógeno do capitalismo explora o território até que sejam extraídas todas as possibilidades de reprodução do capital. Quando o território deixa de ser atraente para o capitalismo ele é abandonado e o desenvolvimento busca novos espaços para a sua estratégia. Nessa situação, o território explorado perde a sua validade. 
O termo desenvolvimento em si já traz muitas discussões. O que é desenvolvimento? Ele é próprio das características de reprodução no capitalismo? É possível pensar em desenvolvimento aliado aos princípios da Economia Solidária? Se buscarmos seu sentido filosófico, o conceito de desenvolvimento se explica pelo movimento em direção ao melhor. Essa é a definição primeira contida no Dicionário de Filosofia (Abaggnano, 2003:241).

Ela tem precedentes no conceito aristotélico de movimento e seu significado otimista é peculiar da filosofia do século XIX estreitamente ligado ao conceito de progresso. Hegel transformou o desenvolvimento numa categoria fundamental da sua filosofia e o exemplificou na história. Hegel ainda destacou que o desenvolvimento pressupõe o fim para o qual se move. Assim, pensar em desenvolvimento é pensar num movimento que atinja a um fim. Se o desenvolvimento é pensado como o movimento em direção a um fim, é possível pensarmos que a economia solidária pode ser um modelo de desenvolvimento para alcançar um fim? Que fim é esse que almejamos na Economia Solidária?

A escala desse desenvolvimento também é objeto de discussão. Local ou territorial? Para além de uma questão de escala, o que está implicado nessa discussão é uma questão conceitual. Tanto um quanto o outro não se restringem a dimensão ou tamanho, mas às relações sociais que se estabelecem no espaço. O local, em sentido estrito, é a localização, um ponto em meio a outros. Por isso, não se trata de uma categoria de análise. Já o território é uma categoria que tem um longo histórico nos estudos geográficos. De maneira geral, o território é pensado como espaço onde há uma relação de apropriação e de pertencimento.

Cabe-nos compreender qual é a diferença entre desenvolvimento territorial e desenvolvimento local. A escolha por um ou outro termo ainda não é unânime. Na economia solidária há uma prevalência do termo desenvolvimento territorial.

A discussão sobre o desenvolvimento territorial e/ou desenvolvimento local deve considerar as origens da discussão dos termos. Ambos partem de um modelo de desenvolvimento endógeno, a partir de atores locais, o que difere dos modelos tradicionais de desenvolvimento que se pautam por estratégias externas que pouco ou nada consideram sobre as características do território onde ações são implantadas. Mas a diferença entre o territorial e o local não se explica apenas por uma questão de terminologia. O local é um ponto no mapa, mas o modelo de desenvolvimento local que se implantou em muitos países se caracteriza por uma estratégia de tornar o local competitivo no contexto da globalização. O Brasil importou esse modelo de desenvolvimento local na busca por fortalecer e tornar competitivas algumas localidades através da formação de redes de pequenas e médias empresas. Mas torná-las competitivas no capitalismo, sem questioná-lo.

O desenvolvimento territorial pode agregar outros componentes a essa discussão. Partir do entendimento do território como esfera de pertencimento e apropriação de uma comunidade abre a perspectiva para pensar numa estratégia que vá para além da esfera econômica considerando que o desenvolvimento também tem que ser para tornar dignas as condições de vida da população. Nesse sentido, pensar a economia solidária como estratégia de desenvolvimento territorial implica em considerar que os princípios que regem os empreendimentos podem ultrapassar o local da produção e pautar a vida da comunidade onde as iniciativas de economia solidária estão presentes

\section{Considerações finais}

Compreendemos que as concepções de desenvolvimento local e de desenvolvimento territorial apresentam projetos distintos. Se a economia solidária pretende ser uma proposta anticapitalista, não é como um modelo de desenvolvimento local que sua virtualidade pode se realizar.

A economia solidária tem uma potência, fundamentada na autogestão, de extrapolar o espaço restrito de seus empreendimentos para atingir a sociedade. Não se pode omitir as dificuldades diárias de reprodução dos empreendimentos econômicos solidários. Mas também não se pode omitir a formação política dos trabalhadores dessas experiências. Ampliando a compreensão sobre o termo tomamos da teoria política a categoria autogestão: 
"trata de um sistema de organização de toda a sociedade, incluindo as instituições políticas, sociais, econômicas e produtivas nas quais inexistam a divisão social do trabalho e a separação entre economia e política, Estado, o mercado e as classes sociais. De acordo com essa proposta revolucionária, a autogestão não se resume aos limites das empresas, mas é um projeto global da sociedade" (Nahas, 2006:37).

Também é como um projeto global da sociedade que Lefèbvre (1973a e 1973b) implica a autogestão. Para o autor "a autogestão entra no projeto global como um aspecto decisivo, mas não exclusivo" (Lefèbvre, 1973a:44).

A Sociologia das Ausências de Boaventura de Sousa Santos (2007) indica um caminho metodológico que visibiliza o que é ocultado pela produção hegemônica do conhecimento. Trata-se, de acordo com Santos (2007:28), "de um procedimento transgressivo, uma sociologia insurgente para tentar mostrar que o que não existe é produzido ativamente como não-existente".

Lefèbvre (1973a:39) enfatiza que o projeto global que propõe só pode resultar de um esforço coletivo, espontâneo e consciente, teórico e prático, para determinar a via e que para a sua elaboração já cooperam "os grupos parciais e diferenciais, sobretudo os que o poder central rejeita para as periferias mentais, sociais, espaciais". Uma relação com a Sociologia das Ausências de Santos (2007) se apresenta na proposta de Lefèbvre (1973a) quando justifica que "se o projeto não se pode elaborar, ou se não possui nenhuma eficácia, é porque os fatos ditos sociais escapam ao pensamento e à ação, porque consistem apenas em acasos e necessidades igualmente cegos, em fluxos e refluxos" (Lefebvre, 1973a:39).

Seguindo esse procedimento metodológico é que temos estudado as experiências da economia solidária pela perspectiva das relações sociais que, baseadas nos princípios da autogestão e da solidariedade, são potencialmente produtoras de relações espaciais. Assim, a busca é por identificar formas de apropriação e de identificação dos trabalhadores dos empreendimentos econômicos solidários com o território onde produzem e reproduzem suas condições de vida.

\section{Referências bibliográficas}

Abbagnano, N. (2003). Dicionário de filosofia. Tradução de Alfredo Bosi. $4^{a}$ edição. São Paulo: Martins Fontes.

Carlos, A.F.A. (2007). Diferenciação socioespacial. Em revista Cidades, Presidente Prudente, 4(6), 45-60, jan-dez.

Fórum Brasileiro de Economia Solidaria (2012). Carta Política da V Plenária Nacional de Economia Solidária. Luiziânia/GO. Disponível em: http://www.fbes.org.br/ index.php?option=com_docman\&task=doc_details\&ltemid=18\&gid=1700 (acesso em 10 de janeiro de 2013).

Haesbaert, R. (2009). O mito da desterritorialização: do "fim dos territórios" à multiterritorialidade. Rio de Janeiro: Bertrand Brasil.

Hespanha, P. et al. (2009). Dicionário internacional da outra economia. Coimbra: Almedina/CES.

Lefèbvre, H. (1973a). A reprodução das relações de produção. Tradução de Antonio Ribeiro e M. Amaral. Porto: Publicações Escorpião (Cadernos O Homem e a Sociedade)

Lefèbvre, H. (1973b). La survie du capitalisme. La re-production des rapports de production. $2^{\circ}$ ed. Paris: Éditions Anthropos.

Nahas, V.G. (2006). Autogestão. In Cattani, A. \& Holzmann, L. (orgs.). Dicionário de Trabalho e Tecnologia. Porto Alegre: Ed. da UFRGS, 36-40.

Singer, P. \& Sousa, A.R. (orgs.) (2003). A economia solidária no Brasil. A autogestão como resposta ao desemprego. $2^{\circ}$ ed. São Paulo: Contexto.

Sousa Santos, B. (2007). Renovar a teoria crítica e reinventar a emancipação social. São Paulo: Boitempo. 